\title{
QUIZ: PACIENTE DE 78 ANOS SOFRE PARADA CARDIORRESPIRATÓRIA QUAL A CAUSA?
}

DOI: $10.5380 /$ rmu.v1i4.40698

Gibran Avelino Frandoloso', João Pedro Pereira da Cunha', Caio Cesar Cervi Lagana1', Gustavo Lenci Marques', Lucas Rathunde ${ }^{1}$

Caso Clínico: Uma paciente de 78 anos, portadora de hipertensão arterial sistêmica e microangiopatia amiloide cerebral, é internada por suspeita de acidente vascular encefálico isquêmico. Faz uso de enalapril, hidroclorotiazida, AAS e clorpromazina. Ao exame físico apresenta-se confusa e com tetraparesia. Nos exames laboratoriais encontramos hipomagnesemia, hipocalemia e hipocalcemia. Demais exames sem alterações. Algumas horas após o internamento evolui com parada cardiorrespiratória, com o seguinte traçado eletrocardiográfico no momento do evento:

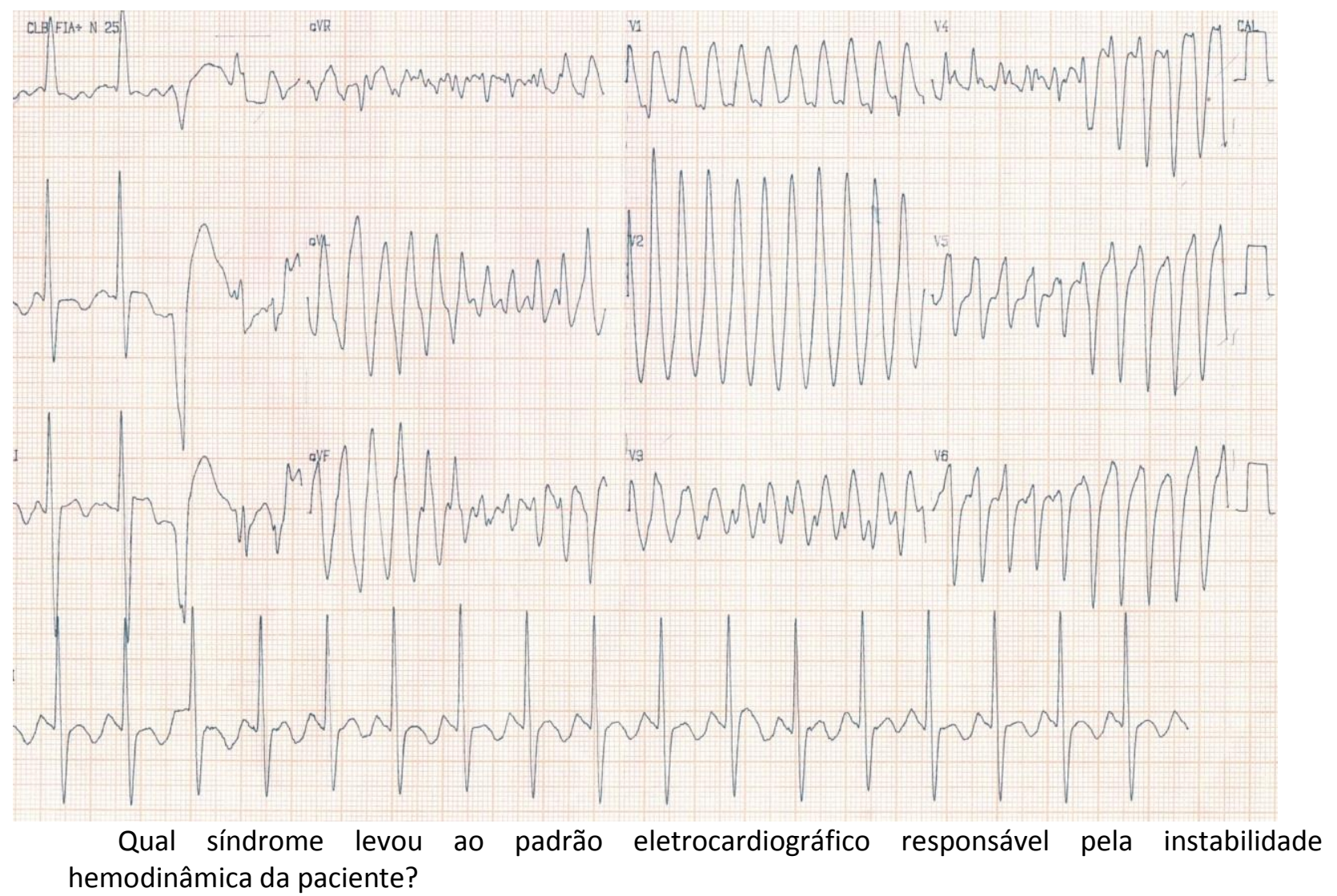
a) Síndrome do PR longo
b) Síndrome do QT longo
c) Síndrome do PR curto
d) Síndrome de Wolff-Parkinson-White
e) Síndrome coronariana aguda 


\section{RESPOSTA: B) SÍNDROME DO QT LONGO}

Esta paciente apresentou uma taquicardia ventricular polimórfica denominada Torsades de Pointes, caracterizada por complexos QRS ora de maior amplitude, ora de menor amplitude. Um intervalo QT longo durante o ritmo sinusal está associado à deflagração dessa taquicardia.

A síndrome do QT longo pode ser congênita ou adquirida, e dentre estas uma causa de grande importância é o prolongamento do intervalo QT induzido por drogas. Os principais medicamentos associados ao intervalo QT longo são alguns antiarrítmicos (como quinidina e sotalol), haloperidol, metadona, pentamidina, entre outros. O uso de clorpromazina, presente nessa paciente, também foi associado à síndrome.

Distúrbios hidroeletrolíticos, em especial hipomagnesemia, hipocalemia e hipocalcemia, também podem prolongar o intervalo QT, além de serem fator de risco para o prolongamento induzido por drogas.

Consideramos um intervalo QT longo aquele maior que $0,44 \mathrm{~s}$. Porém a frequência cardíaca é uma variável importante para a duração desse intervalo, portanto para sua melhor interpretação é necessário "corrigir" o QT.
Há diversos métodos para esse cálculo; uma possibilidade é usar a fórmula de Bazett:

$$
\mathrm{QTC}=\mathrm{QT} / \mathrm{V} R \mathrm{R},
$$

onde QTc é o QT corrigido e RR é a duração do intervalo R-R. Por exemplo, se a frequência cardíaca é 60bpm, o intervalo R-R dura 1 segundo, e o QTc será igual ao QT medido. Quanto maior a frequência cardíaca, maior será o QTc em relação ao QT medido.

O tratamento consiste em identificar e corrigir as possíveis causas da Síndrome do QT Longo, interrompendo o uso das eventuais drogas responsáveis pelo quadro. A arritmia em Torsades de Pointes deve ser manejada como qualquer taquicardia ventricular polimórfica, revertendo o ritmo com desfibrilação elétrica se necessário.

\section{REFERÊNCIAS BIBLIOGRÁFICAS}

1. Roden, D. M. (2004). Drug-induced prolongation of the QT interval. The New England Journal of Medicine, 350(10), 1013-22.

2. Roden, D. M. (2008). Long-QT Syndrome. The New England Journal of Medicine, 358(2), 169-176. 